九州大学学術情報リポジトリ

Kyushu University Institutional Repository

Changes in the Water Content and Germination Rate During Seed Desiccation and Their InterSpecific Differences among Zizania Species

Jin, I l-Doo

College of Agriculture and Life Science, Sunchon Nat' I University, Korea

Yun, Song Joong

College of Agriculture and Life Science, Chonbuk Nat' I University, Korea

Matsuishi, Yuko

Graduate School of Bioresource and Bioenvironmental Sciences, Kyushu Unviersity

Inoue, Mar $\mathrm{i}$

Faculty of Agriculture, Kyushu Unviersity

https://doi.org/10.5109/4670

出版情報：九州大学大学院農学研究院紀要. 50 (2)，pp.573-583，2005-10-01. Faculty of Agriculture, Kyushu University

バージョン：

権利関係 : 


\title{
Changes in the Water Content and Germination Rate During Seed Desiccation and Their Inter-Specific Differences among Zizania Species
}

\author{
Il-Doo JIN ${ }^{1}$, Song Joong YUN ${ }^{2}$, Yuko MATSUISHI ${ }^{3}$ \\ and Mari IWAYA-INOUE*
}

\author{
Laboratory of Crop Science, Division of Agricultural Botany, Department of Plant Resources, \\ Faculty of Agriculture, Kyushu University, Fukuoka 812-8581, Japan \\ (Received June 30, 2005 and accepted July 26, 2005)
}

\begin{abstract}
Wild rice (Zizania palustris) is a newly cultivated crop that is known for its quality compounds of human health benefits. Zizania seeds are extremely sensitive to drought during the maturing and storage period. This study was conducted to examine the effect of seed water content on germination in three Zizania species, Z. aquatica, Z. latifolia and Z. palustris that have different morphological grain characteristics. Grain water content in the range of 9 to $83 \%$ showed a positive correlation with germination rate and speed. It was greatly affected by humidity during seed desiccation period. Seed water content was higher in the varieties or strains of larger grains than in those of smaller grains, also, in unhulled than in hulled grains. Seed water content decreased rapidly within 2 weeks of desiccation. Decreased seed water content was closely related to the decreased germination rate and speed in most Zizania species. Seed germination rate was maintained over $80 \%$ in water content over $35 \%$ in all $Z i z a n i a$ species except for $Z$. latifolia from Sunchon bay that showed very low germination. However, seed germination at water content below $35 \%$ was significantly different by the seed size but not necessarily by the species. Seed viability of $50 \%$ was observed at $20 \%$ of seed water content in the small grain $Z$. aquatica from Virginia, while at about $10-13 \%$ of water contents in the large grain $Z$. aquatica from Iowa and $Z$. palustris. Taken together, the results from this study indicate that water content of mature wild rice seeds is a critical factor in germination, and it is affected mainly by humidity during seed maturation. Post-harvest practices to maintain seed water content in the range of 20 to $50 \%$ should improve wild rice seed viability.
\end{abstract}

\section{INTRODUCTION}

The genus Zizania consists of four species, Z. aquatica, Z. palustris and Z. texana that are native in north America and $Z$. latifolia, in east Asia (Dore, 1969). All of them are aquatic grasses grown spontaneously in the shallow lake, sluggish river and stream. Among them $Z$. palustris, so called wild rice, had historically been gathered from natural population and used as major food by the Sioux and Chippewa Indian tribes that lived in the Great Lake region (Steeves, 1952). In recent years, wild rice consumption is steadily increasing as a nutritious food. Wild rice contains high quality protein and fat, much of minerals such as $\mathrm{Mg}, \mathrm{P}, \mathrm{Fe}$ and $\mathrm{K}$, vitamin $\mathrm{B}_{1}$ and $\mathrm{B}_{2}$, and nicotinic acid etc. It has unique

1 College of Agriculture and Life Science, Sunchon Nat'l University, Korea

2 College of Agriculture and Life Science, Chonbuk Nat'l University, Korea

${ }^{3}$ Laboratory of Crop Science, Division of Agricultural Botany, Department of Plant Resources, Graduate School of Bioresource and Bioenvironmental Sciences, Kyushu University

* Corresponding author (E-mail: mariino@agr.kyushu-u.ac.jp) 
texture and nut-like flavor (Duvel, 1906; Terrell and Wiser, 1975; Anderson, 1976; Oelke, 1976; Swain et al., 1978, Wang et al., 1978; Watts and Dronzek, 1981). Therefore, wild rice is a newly cultivated crop undergoing domestication at Minnesota and California, USA, since 1960s. However, wild rice cultivars still exhibit many characteristics of wild grasses: complex dormancy requirement, efficient seed dispersal mechanisms and asynchronous flowering (Harlen et al., 1973).

Zizania seeds are extremely sensitive to drying and thus drought is a well known limiting factor in wild rice production (Brown and Scofield, 1903; Duvel, 1906; Legget, 1923; Muenscher, 1936; Barton, 1939; Simpson, 1966; Cardwell et al., 1978: Atkins et al., 1987; Probert and Brierley, 1989; Probert and Longley, 1989; Kovach and Bradford, 1992; Vertucci et $a l ., 1994$, Vertucci et $a l ., 1995)$. Many factors influence seed viability during desiccation (Kermode et al., 1990). Relative vapor pressure, temperature and seed maturity all influence seed survival during drying. To retain viability during drying, seed water content must be high enough to prevent damage from desiccation and low enough to prevent freezing. Because of the increased vapor pressure at high temperatures, seeds can survive with lower water contents at higher temperatures than at lower temperatures (Vertucci et al., 1994). Horne and Kahn (2000) reported that $Z$. palustris and $Z$. texana seeds were intolerant to short-term desiccation. Humidity is critical in seed survival after harvest. Dried seeds survived only 5 to 6 days at $14 \%$ relative humidity $(\mathrm{RH})$, but they survived 2 to 3 weeks at $75 \%$ RH (Horne and Kahn, 2000).

The objective of present work was to investigate effect of seed water contents on germination in the Zizania species, Z. aquatica, Z. latifolia and Z. palustris.

\section{MATERIALS AND METHODS}

Zizania aquatica and $Z$. palustris plants were cultivated in the paddy field of experimental farm at Sunchon National University, Korea. Seeds of two species were obtained from the University of Minnesota, USA. The seeds of $Z$. latifolia were collected from the natural population at Sunchon bay area and lake in Goheung County near the Sunchon National University. Only black or dark green seeds were collected and were used in the experiments.

Harvested seeds were subjected to desiccation for 5 weeks at room temperature. After desiccation, seed length and width were measured and length/width ratio was calculated. One thousand seed weight was calculated based on seed weight of 100 hulled seeds.

To investigate the relationship between seed water condition and germination, seed were subjected to four different treatments: (1) air dried seeds 5 weeks in room condition (air-dried seed), (2) air-tight sealing of seeds immediately after harvest under vacuum to keep water condition as harvested seeds (water content at harvest), (3) sealing of seeds in air-tight storage bags with wet filter paper inside (moist seed) and (4) submersion of seeds in water (submerged seed). After treatments, the seeds of each treatment were sealed air tight in locking plastic envelopes and stored in a $3^{\circ} \mathrm{C}$ incubator for 5 months. After 5 months storage, seed germination was examined for each treatment at $25^{\circ} \mathrm{C}$ for 30 days. The germination speed was determined by counting the days to germination after transferring into $25^{\circ} \mathrm{C}$ water. 
The seeds were prepared two groups, both unhulled and hulled seeds, to establish the influence of seed water contents on germination. Each of 100 seeds from every variety or strains of three Zizania species was dried at room temperature with one-week intervals for 5 weeks. After desiccation treatment, the seeds were measured gravimetrically and stored in a $3^{\circ} \mathrm{C}$ incubator for 6 months to break any dormancy. After cold treatment, seeds were transferred into water at $25^{\circ} \mathrm{C}$ and germination examined daily for 30 days. Additionally, both unhulled and hulled seeds were prepared to determine the dry weight for calculating seed water contents. Each of 100 seeds from above varieties or strains was dried at $105^{\circ} \mathrm{C}$ for $24 \mathrm{~h}$ and measured gravimetrically. The water contents of desiccated seeds were calculated by subtracting dry weight of air-dried seeds from that of seed weight for each treatment. All experiments were conducted with 3 replications in a completely randomized design.

\section{RESULTS}

\section{Differences in seed size among $Z$. aquatica, $Z$. latifolia and $Z$. palustris}

As shown in Table 1 , the seed length was longer in $Z$. aquatica and than in $Z$. latifolia. Significant difference in seed length was recognized in the strains of $Z$. aquatica and $Z$. latifolia. Seeds of $Z$. palustris were shorter than those of $Z$. aquatica but longer than $Z$. latifolia. No Significant difference was observed between two varieties of $Z$. palustris, Netum and North California \#3. Meanwhile, seed width was significantly wider in $Z$. palustris than in the two species, $Z$. aquatica and $Z$. latifolia, showing little difference between the strains within the species. The length/width ratio was higher in the strains of $Z$. aquatica than those of other two species. Difference in the length/width ratio was recognized in the strains of $Z$. aquatica and $Z$. latifolia but not in those of $Z$. palustris. The weight of air-dried seeds of $Z$. palustris was heaviest among the three $Z i z a n i a$ species with no difference between two cultivars followed by that of $Z$. aquatica and Z. latifolia.

Table 1. Seed size and weight of the species in strains of Zizania.

\begin{tabular}{|c|c|c|c|c|}
\hline $\begin{array}{l}\text { Species/ } \\
\text { varieties or strains }\end{array}$ & $\begin{array}{l}\text { Length of seed } \\
\text { (Mean } \pm \text { S. D.) }\end{array}$ & $\begin{array}{l}\text { Width of seed } \\
\text { (Mean } \pm \text { S. D.) }\end{array}$ & $\begin{array}{l}\text { Length/Width } \\
\text { (Mean } \pm \text { S. D.) }\end{array}$ & $\begin{array}{c}\text { Grain weight } \\
\text { (Mean } \pm \text { S. D.) }\end{array}$ \\
\hline Zizania aquatica & $(\mathrm{mm})$ & $(\mathrm{mm})$ & & (mg) \\
\hline Iowa Coll. & $11.02 \pm 0.25$ & $1.28 \pm 0.08$ & $8.65 \pm 0.62$ & $18.70 \pm 0.25$ \\
\hline Virginia Coll. & $13.66 \pm 0.45$ & $1.07 \pm 0.09$ & $12.89 \pm 1.26$ & $13.20 \pm 0.64$ \\
\hline Zizania latifolia & & & & . \\
\hline Sunchon Coll. & $7.04 \pm 0.22$ & $1.18 \pm 0.06$ & $5.98 \pm 0.26$ & $8.99 \pm 0.38$ \\
\hline Goheung Coll. & $7.96 \pm 0.21$ & $1.13 \pm 0.09$ & $7.08 \pm 0.64$ & $9.35 \pm 0.12$ \\
\hline Zizania palustris & & & & \\
\hline Netum & $10.73 \pm 0.24$ & $1.72 \pm 0.17$ & $6.31 \pm 0.63$ & $24.97 \pm 0.56$ \\
\hline North Cal. \#3 & $10.49 \pm 0.48$ & $1.55 \pm 0.14$ & $6.80 \pm 0.42$ & $26.51 \pm 0.27$ \\
\hline
\end{tabular}

Each of 100 seeds from every variety or strains was used as materials. 


\section{Influence of seed water conditions at the dormancy breaking period on the germination rate and speed}

The germination rate and speed of intact seeds of $Z$. palustris (cv. Netum) after 5 months storage at $3{ }^{\circ} \mathrm{C}$ following the four different treatments of seed water condition are shown in Table 2 . Only $1 \%$ of the air-dried seeds with $9 \%$ of water content germinated after 18 days on average from soaking into water at $25^{\circ} \mathrm{C}$. The seeds maintained water content at harvest and those wetted on moistened filter paper showed similar germination rates with 32 to $34 \%$ and many seeds were decayed by microbial growth. However, the former required 13.9 days and the latter 9.5 days on average to germination. Any significant difference in the water content between both seed was not recognized. About $90 \%$ of the seeds submerged in water germinated within 6 days on average (Table 2).

Table 2. Effects of different water conditions on the germination ratio and speed of Zizania palustris cv. Natum stored for 5 months at $3^{\circ} \mathrm{C}$.

\begin{tabular}{lccc}
\hline $\begin{array}{l}\text { Water conditions } \\
\text { of seeds }\end{array}$ & $\begin{array}{c}\text { Water contents(\%) } \\
\text { Mean } \pm \text { S. D. }\end{array}$ & $\begin{array}{c}\text { Germination (\%) } \\
\text { Mean } \pm \text { S. D. }\end{array}$ & $\begin{array}{c}\text { Days to germination } \\
\text { Mean } \pm \text { S. D. }\end{array}$ \\
\hline Air dried seed & $9.0 \pm 0.10$ & $1.3 \pm 1.89$ & $18.0 \pm 8.49$ \\
Harvested seed & $70.9 \pm 7.73$ & $34.0 \pm 7.12$ & $13.9 \pm 2.10$ \\
Moist seed & $76.4 \pm 4.62$ & $32.7 \pm 9.84$ & $9.5 \pm 1.99$ \\
Submerged seed & $82.5 \pm 4.53$ & $89.3 \pm 2.49$ & $5.9 \pm 0.13$ \\
\hline
\end{tabular}

\section{Relationship between seed desiccation and germination}

Changes of the grain weight and water content during desiccation period

The grain weight rapidly changed within 2 weeks after desiccation in room temperature with no differences among species and between unhulled and hulled grains (Fig. 1). The water content was variable among species or between unhulled and hulled grains. The water content was higher in the varieties or strains of larger grains than those of smaller grains. Similarly, water content was higher in unhulled than in hulled grains. Rapid reduction of water content was recognized within 2 weeks of desiccation. Grain water content decreased more rapidly in large and unhulled grains than in small and hulled grains (Fig. 2).

\section{Desiccation effect on the germination ratio and speed}

Germination rate of Zizania grains stored at $3^{\circ} \mathrm{C}$ for 6 months after desiccation treatment for 1 to 5 weeks is shown in Fig. 3. The germination rate varied significantly among Zizania species. Germination rate was drastically reduced by the desiccation treatment longer than 3 weeks in all Zizania species. Germination of the two large grain varieties, Netum and North California \#3 of Zizania palustris and Z. aquatica from Iowa was higher for up to 2 weeks of desiccation but drastically decreased in 3 to 4 weeks of desiccation. However, germination rate of small grain $Z$. aquatica from Virginia rapidly decreased in 1 to 2 weeks of desiccation and no germination was observed after 3 weeks of desiccation. Germination rate of the control grains of small grain $Z$. latifolia from Sunchon bay was too low to be affected by any desiccation treatment (Fig. 3). 


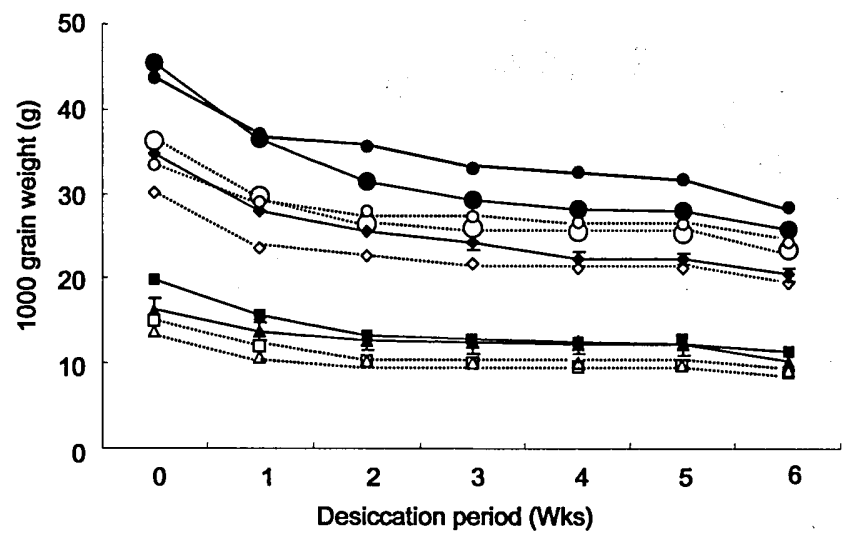

Fig. 1. Changes in grain weight during air-drying desiccation of Zizania species. Rhomboid, Z. aquatica Iowa; triangle, Z. aquatica Virginia; square, Z. latifolia Sunchon; large circle, Z. palustris Netum; small circle, $Z$. palustris NC \#3. Closed symbols indicate unhulled seeds while open symbols indicate hulled seeds. Each of 100 seeds from every variety or strains was used as materials. 3 replications were conducted in each experiment. Symbols represent the mean and SD bars are not visible when they are smaller than symbols.

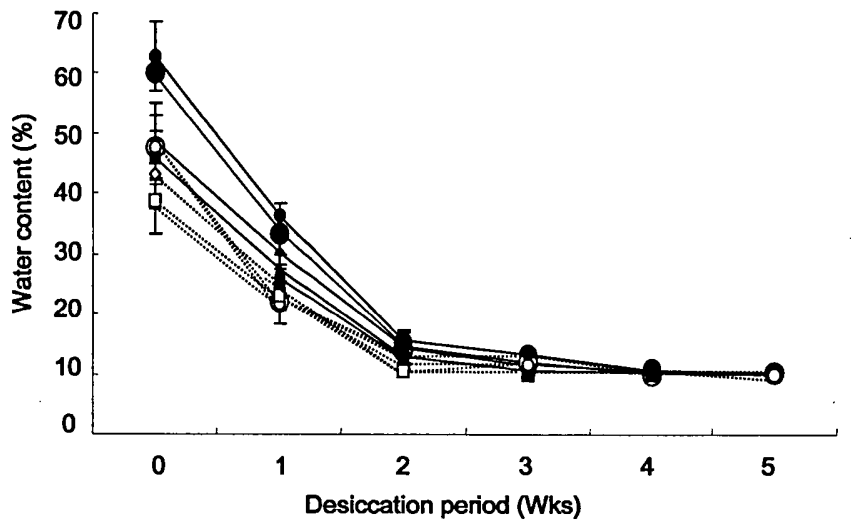

Fig. 2. Changes in water content during air-drying desiccation of $Z$ izania species. Rhomboid, $Z$. aquatica Iowa; triangle, $Z$. aquatica Virginia; square, $Z$. latifolia Sunchon; large circle, $Z$. palustris Netum; small circle, $Z$. palustris NC \#3. Closed symbols indicate unhulled seeds while open symbols indicate hulled seeds. SD bars are not visible when they are smaller than symbols. The other captions are the same as in Fig. 1. 


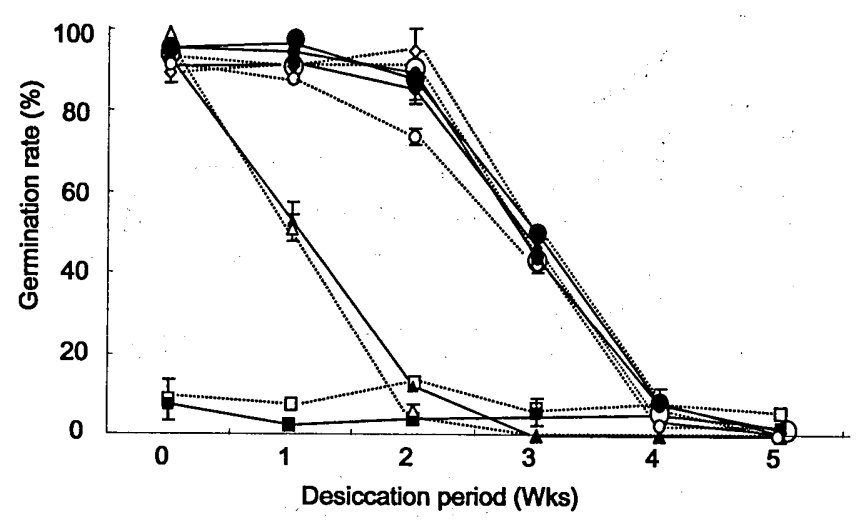

Fig. 3. Changes in germination ratio during air-drying desiccation of Zizania species. Rhomboid, $Z$. aquatica Iowa; triangle, $Z$. aquatica Virginia; square, $Z$. latifolia Sunchon; large circle, $Z$. palustris Netum; small circle, Z. palustris NC \#3. Closed symbols indicate unhulled seeds while open symbols indicate hulled seeds. SD bars are not visible when they are smaller than symbols. The other captions are the same as in Fig. 1.

The grains of Zizania germinated with the protrusion of the epiblast and coleoptile from 3 days to 12 days on average after soaking the seeds into water at $25^{\circ} \mathrm{C}$. The days to germination were significantly different among varieties and strains of Zizania species and delayed significantly by desiccation longer than 3 weeks in most species (Fig. 4).

\section{Relationship between seed water content and germination rate and speed}

The germination of Zizania seeds was mainly affected by seed water contents. The desiccated seeds maintaining over $15 \%$ of water content fully germinated except for the small grains $Z$. aquatica collected from Virginia and $Z$. latifolia from Sunchon bay (Fig. 5.). It seems that there is critical water content differentiating a delicate difference in germination between unhulled and hulled grains, and among varieties and strain.

The grains of Zizania stored at $3^{\circ} \mathrm{C}$ for 6 months with water content over $15 \%$ of per dry weight germinated within 3 to 8 days on average after immersing the seeds into water at $25^{\circ} \mathrm{C}$ with some variations among varieties and strains, and also between unhulled and hulled grains (Fig. 6). Unhulled grains of all the varieties and strains were required more days for germination. And they showed similar tendency to undesiccated controls. However, the days to germination of the seeds with water content per dry weight below $15 \%$ increased drastically with decreasing water content (Fig. 6 ).

\section{Relationship between germination rate and germination speed}

As shown in Fig. 7, the germination rate was closely related with the days to germination. The desiccated seeds of Zizania with germination rate over $80 \%$ germinated within about 7 days after soaking into water at $25^{\circ} \mathrm{C}$. However those with germination rate 


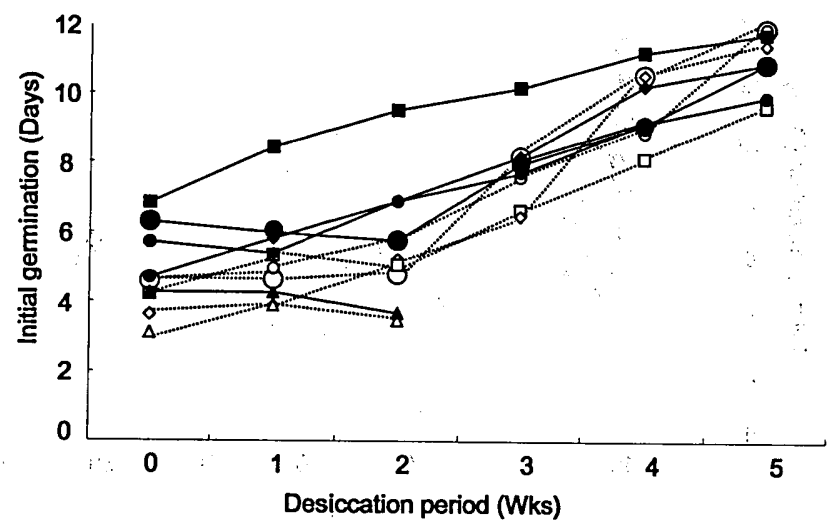

Fig. 4. Changes in germination speed during air-drying desiccation of $Z$ izania species. Rhomboid, $Z$. aquatica Iowa; triangle, $Z$. aquatica Virginia; square, $Z$. latifolia Sunchon; large circle, $Z$. palustris Netum; small circle, Z. palustris NC \#3. Closed symbols indicate unhulled seeds while open symbols indicate hulled seeds. The other captions are the same as in Fig. 1.

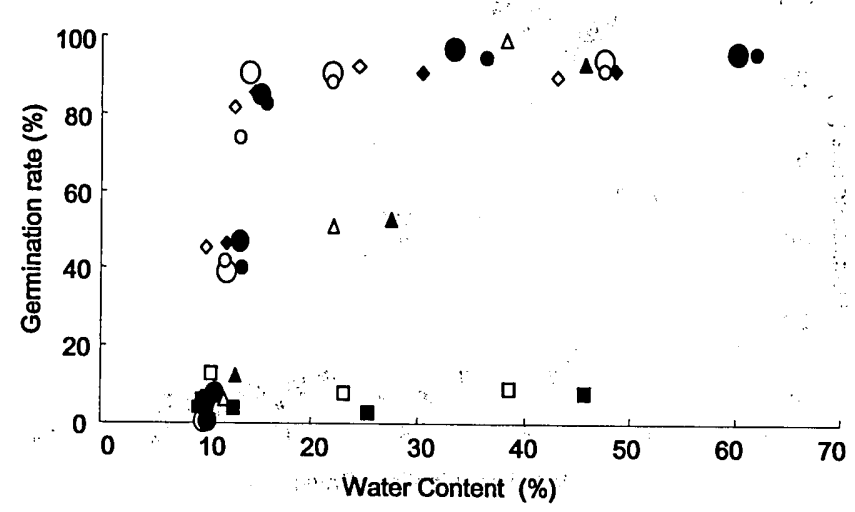

Fig. 5. Relationship between water content and germination ratio of $Z$ izania species. Rhomboid, $Z$. aquatica Iowa; triangle, $Z$. aquatica Virginia; square, $Z$. latifolia Sunchon; large circle, $Z$. palustris Netum; small circle, Z. palustris NC \#3. Closed symbols indicate unhulled seeds while open symbols indicate hulled seeds. The other captions are the same as in Fig. 1. 


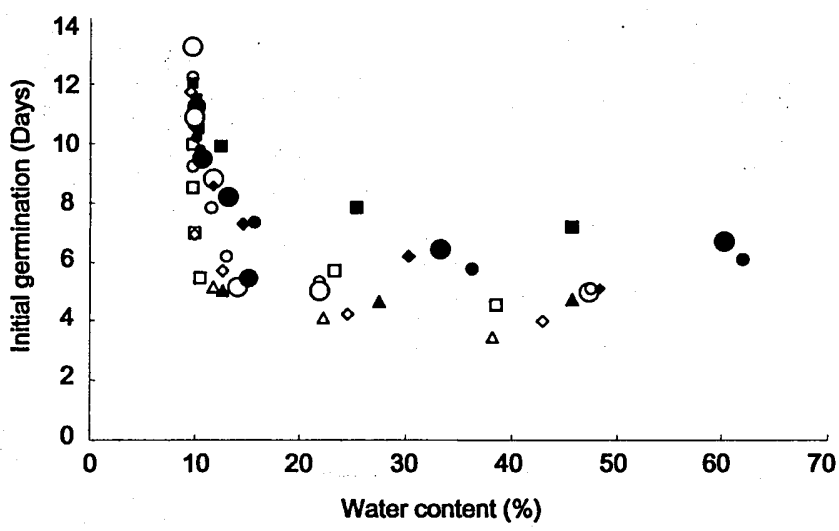

Fig. 6. Relationship between water content and days to germination of Zizania species. Rhomboid, $Z$. aquatica Iowa; triangle, $Z$. aquatica Virginia; square, $Z$. latifolia Sunchon; large circle, $Z$. palustris Netum; small circle, $Z$. palustris NC \#3. Closed symbols indicate unhulled seeds while open symbols indicate hulled seeds. The other captions are the same as in Fig. 1.

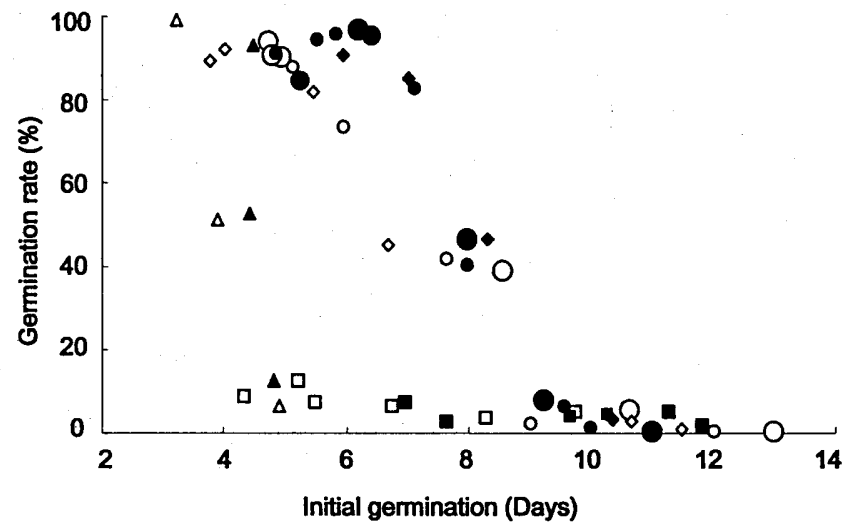

Fig. 7. Relationship between germination ratio and speed of Zizania species. Rhomboid, Z. aquatica Iowa; triangle, Z. aquatica Virginia; square, Z. latifolia Sunchon; large circle, Z. palustris Netum; small circle, Z. palustris NC \#3. Closed symbols indicate unhulled seeds while open symbols indicate hulled seeds. The other captions are the same as in Fig. 1. 
below $10 \%$ germinated after 9 days except for the small grains strains of $Z$. aquatica from Virginia and $Z$. latifolia from Sunchon bay respectively. And the grains showing 40 to $5 \%$ germination rate germinated within 7 to 9 days after soaking into water at $25^{\circ} \mathrm{C}$ (Fig. 7).

\section{DISCUSSION}

Water content of mature wild rice seeds is a critical factor for the survival of embryo during seed storage and for normal germination. Results from this study confirmed the early findings and also demonstrated that critical water content is affected by grain size and genotypes. The importance of water status in matured wild rice seed for germination was firstly suggested by Simpson (1966) by showing the effect of water content on the viability of embryos. The viability of embryos in caryopsis dried for 2 or 3 weeks was high but it decreased drastically in those dried for longer than 3 weeks. Our results from large grain Zizania species, including the two varieties of $Z$. palustris and a strain of $Z$. aquatica from Iowa, are in good agreement with the previous findings. However, the small grain $Z$. aquatica from Virginia was very sensitive to drying. Seed germination was drastically reduced within a week after desiccation treatment (Fig. 3). Contrastingly, germination of $Z$. latifolia seeds was little affected by desiccation treatment for up to 5 weeks, though seed germination of control seed was as low as $10 \%$. In general, the results indicate a genotypic effect on the seed sensitivity to desiccation.

Seed water content was directly affected by the desiccation treatment, showing a clear time-dependent decrease in all Zizania species tested (Fig. 2). Decreased water content was closely related to the decreased germination rate and speed in most Zizania species (Figs. 3, 4, 5 and 6), suggesting the importance of seed water content for seed viability. Wild rice grains are known to be sensitive to desiccation (Brown and Scofield, 1903; Duvel, 1906; Legget, 1923; Muenscher, 1936; Barton, 1939; Simpson, 1966; Cardwell et al., 1978: Atkins et al., 1987; Probert and Brierley, 1989; Probert and Longley, 1989; Kovach and Bradford, 1992; Vertucci et al., 1994, Vertucci et al., 1995; Horne and Kahn, 2000). Thus, the results suggest that desiccation effect on seed germination may be manifested by seed water content. Similarly, Kovach and Bradford (1992) reported that no seed with moisture contents of $6-8 \%$ by fresh weight base survived longer than 4 weeks at $5^{\circ} \mathrm{C}$.

Analysis of relationship between seed water content and germination rate indicates a critical water content during desiccation for Zizania seed survival. Most Zizania seeds except for $Z$. latifolia from Suchon bay showed $50 \%$ germination with the water content at about 13 to $20 \%$. This result is in agreement with previous reports (Ntuli et al., 1997; Vertucci et al., 1995). As grains mature, resistance to drying is enhanced. Desiccation during seed harvest rather than water imbibition during germination is responsible for damage in dried Zizania grains (Vertucci et al., 1995). During cold dormancy, seed water content must be high enough to prevent desiccation damage, but low enough to prevent freeze damage. Viability of embryos decreases when embryos are dried to the critical water content below $40 \%$ at any storage period. Ntuli et al. (1997) reported that water contents in the embryonic axis and whole seeds were about $36-40 \%$ and $8-13 \%$ in the whole seeds after desiccation for 3 weeks.

Further analysis of relationship between seed water content and germination rate 
indicates a possible effect of size on seed water content during desiccation and germination. Seed germination rate was maintained over $80 \%$ in water content over $35 \%$ in all $Z i z a n i a$ species except for $Z$. latifolia collected from Sunchon bay that showed very low germination (Fig. 5). Interestingly, however, seed germination at water content below $35 \%$ showed significant difference by the seed size but not necessarily by the species. Seed viability of $50 \%$ was observed at $20 \%$ of seed water content per dry weight in the small grain $Z$. aquatica from Virginia, while at about $10-13 \%$ of grain water contents in the large grain $Z$. aquatica from Iowa and $Z$. palustris. However, difference in seed viability controlled by the size was not observed in the seeds whose water content was about 8-10\% per dry weight. This result may suggest the presence of variations in response to desiccation and cold stresses among and within Zizania species.

Germination speed of wild rice seeds is affected by many factors. Among them dormancy breaking period in cold water (Probert and Longley, 1989; Vertucci et al., 1995) and temperature at germination play critical roles (Simpson, 1966). Under the controlled dormancy breaking and germination conditions, germination speed was significantly affected by seed water content. No species- or seed size-specific effect on germination speed was apparent. A negative correlation was recognized between germination rate and days to germination at $1 \%$ probability level $(n=54, r=0.7114)$. This result may indicate that seed water content during desiccation affects germination rate than germination speed.

In conclusion, water content of mature wild rice seeds is a critical factor in germination, and it is affected mainly by water conditions during seed maturation. Post-harvest practices to maintain seed water content in the range of 20 to $50 \%$ should improve wild rice seed viability.

\section{ACKNOWLEDGMENT}

This work was supported by JSPS (Japan Society for the Promotion of Science) Grant in Aid for Scientific Research to IJ and MII.

\section{REFERENCES}

Anderson, R. A. 1976 Wild rice: Nutritional review. Cereal Chem., 53: 949-955

Atkins, T. A., A. G. Thomas and J. M. Stewart 1987 The germination of wild rice seed in response to diurnally fluctuating temperatures and after-ripening period. Aquatic Bot., 29: 245-259

Barton, L. V. 1939 Experiments at Boyce Thompson Institute on germination and dormancy in seeds. Sci. Hort., 7: 186-193

Brown, E. and C. S. Scofield 1903 Wild rice, its use and propagation. USDA Bureau of Plant Industry Bulletin, 50: 12-24

Cardwell, V. B., E. A. Oelke and E. A. Elliot 1978 Seed dormancy mechanism in wild rice (Zizania aquatica). Agron. J., 70: $481-488$

Dore, W. G. 1969 Wild rice. Can. Dept. Agric. Publ., 1393: 1-84

Duvel, J. W. T. 1906 The germination and storage of wild rice seed. USDA Bureau of Plant Industry Bulletin, 90: 1-13

Harlan, J. R. J. M. J. De Wet and E. G. Price 1973 Comparative evolution of cereals. Evolution, 27: 311-325

Horne F. R. and A. B. Kahn 2000 Water loss and viability in Zizania (Poaceae) seeds during short-term desiccation. Am. J. Bot., 87: 1707-1711 
Kermode, A. R., J. D. Bewley, J. Dasgupta and S. Misra 1990 The transition from seed development to germination: a key role for desiccation? Hort. Sci., 21: 1113-1118

Kovach, D. A. and K. J. Bradford 1992 Imbibitional damage and desiccation tolerance of wild rice (Zizania palustris) seeds. J. Exp. Bot., 43: 747-757

Muenscher W. C. 1936 Storage and germination of seeds of aquatic plants. Cormell Agric. Exp. Stn. Bull., 652: 3-17

Ntuli, M. T., P. Berjak, N. W. Pammenter and M. T. Smith 1997 Effects of temperature on the desiccation responses of seeds of Zizania palustris Seed Sci. Res., 7: 145-160

Oelke, E. A. 1976. Amino acid content in wild rice (Zizania aquatica L.) grain. Agron. J., 68: 146-148

Probert, R. J. and E. R. Brierley 1989 Desiccation intolerance in seeds of Zizania palustris is not related to developmental age or the duration of post-harvest storage. Ann. Bot., 64: 669-674

Probert, R. J. and P. L. Longley 1989 Recalcitrant seed storage phygiology in three aquatic grasses (Zizania palustris, Spartina anglica and Porteresia coarctata). Ann. Bot., 63: 53-63

Simpson, G. M. 1966 A study of germination in the seed of wild rice (Zizania aquatica). Can. J. Bot., 44: $1-9$

Steeves, T..A. 1952 Wild rice-Indian food and modern delicacy. Econ. Bot., 6: 107-142

Swain, B. W., H. L. Wang and C. W. Hesseltine 1978 Note on vitamins and minerals of wild rice. Cereal Chem., 55: $412-414$

Terrell, E. E. and W. J. Wiser 1975 Protein and lysine contents in grains of three species of wild rice (Zizania; Gramineae). Bot. Gaz., 136: 312-316

Vertucci, C. W., J. Crane, R. A. Porter and E. A. Oealke 1994 Physical properties of water in Zizania embryos in relation to maturity status, water content and temperature. Seed Sci. Res., 4: 211-224

Vertucci, C. W., J. Crane, R. A. Porter and E. A. Oealke 1995 Survival of Zizania embryos in relation to water content, temperature and maturity status. Seed Sci. Res., 4: 211-224

Wang, H. L., E. W. Swain, C. W. Hesseltine and M. R. Gumbmann 1978 Protein quality of wild rice. J. Agr. Food Chem., 26: 309-312

Watts, B. M. and B. L. Dronzek 1981 Chemical composition of wild rice grain. Can. J. Plant Sci., 61: $437-441$ 